\title{
A Welcome Note
}

Greetings! As a new co-Editor-in-Chief of Seminars of Interventional Radiology, I'm excited about the prospect of continuing the strong tradition of the journal and eager to begin. First and foremost, I would like to thank and recognize Dr. Peter Mueller for his tireless and invaluable service for the past 17 years. Dr. Mueller is not replaceable and I'm happy that he has agreed to help me during this transition period.

Just who am I? I am currently an Associate Professor of Radiology and Section Chief of Vascular and Interventional Radiology at the University of Chicago Hospitals. Like my predecessor, I have a strong affinity for sports. In some ways we're both cursed-he has the BoSox (well, I guess after this year maybe the curse has been lifted) and I have the Cubs. In other ways we're pretty fortunate - he has the Patriots and I lived in Chicago during the Bulls' 6 NBA titles. Unlike Dr. Mueller, I hate ice hockey and all other cold-weather sports (I grew up in Hawaii). In fact, I consider the term "winter recreation" to be somewhat of an oxymoron. My father (recently retired) was a private practice radiologist for over 30 years and wife is an academic thoracic radiologist. Like many of you, I remain active in diagnostic radiology, spending 2 days per week reading abdominal CTs, MRI's and ultrasound exams.

My plans for the journal are not grandiose. I do not anticipate any impending major changes rather I would like to "continue the course" and enrich the journal with a few minor (but hopefully valuable) additions. As an academic radiologist, one of my foremost responsibilities involves training residents and fellows. To that end, I am introducing a new section in each issue that will be devoted to our trainees. This "Fellow's Corner" will consist of a "How I Do It" section and a "Morbidity and Mortality" case. Initially, I will write these sections, but if well received I hope to solicit other interventional radiologists for their input and perhaps even expand the idea into a "point vs. counterpoint" format. Of course, "How I Do It" is not intended to be comprehensive and will reflect my own training, experience, and biases. When I am aware of competing techniques, I will explain my rationale for choosing one versus another and defend my choices.

The Morbidity and Mortality case will reflect some type of IR misadventure. I plan to include problems that were resolved in the VIR suite as well as others that were not. I find that complication cases are particularly compelling. I often ponder the "worst case scenario" whenever I'm involved in a particular procedure and take precautions to minimize the risks of untoward events. Since I'm in a busy training program, sometimes the worst case scenario doesn't involve the patient. Rather, it is a trainee stabbing me with a bloody needle, bouncing a ceiling-mounted lead shield off my head, or poking me in the eye with the back end of a contaminated Amplatz wire (all attempted by my fellows and residents at one point or another). More often, complications that come to mind are rare disasters that I've thankfully only read about. Complications arise in a variety of ugly shapes and forms and are usually humbling, and always educational. I have learned a great deal from other interventionalists' misfortune and I hope describing a few of my mistakes will be educational also.

Finally, I would like to hear feedback from youour raison-d'etre. Seminars in Interventional Radiology is your journal and should reflect your needs and interests. Upcoming subjects include venous ablation, practice management, and complications in interventional radiology. I welcome constructive criticism, suggestions for improvement, and possible topics for future issues.

Brian Funaki, M.D. Co-Editor in Chief ${ }^{1}$

Transplant Interventions; Editor in Chief, Peter R. Mueller, M.D.; Guest Editor, Ravi Murthy, M.D. Seminars in Interventional Radiology, volume 21, number 4, 2004. Address for correspondence and reprint requests: Brian Funaki, M.D., Section of Vascular and Interventional Radiology, University of Chicago Hospitals, 5840 S. Maryland Avenue, MC 2026, Chicago, IL 60637. ${ }^{1}$ Associate Professor and Section Chief, Section of Vascular and Interventional Radiology, and Section of Abdominal Imaging, University of Chicago Hospitals, Chicago, Illinois. Copyright (C) 2004 by Thieme Medical Publishers, Inc., 333 Seventh Avenue, New York, NY 10001, USA. Tel: +1(212) 584-4662. 07399529,p;2004,21,04,219,219,ftx,en;sir00260b. 